\title{
Optimizing Spillway Capacity With an Estimated Distribution of Floods
}

\author{
Daniel Resendiz-Carrillo and Lester B. Lave
}

\author{
Department of Engineering and Public Policy, Carnegie Mellon University, Pittsburgh, Pennsylvania
}

\begin{abstract}
A model of social cost minimizing spillway capacity for dams is constructed using (1) the estimated distribution of peak flows from historical data, (2) the estimated relationship between spillway capacity and cost, and (3) a characterization of downstream flood damage from dam failure. Net social cost is the sum of construction costs and expected flood damage. This model is applied to data for the Rio Grande River at Embudo, New Mexico. Minimum social cost is attained at a spillway capacity much smaller than that needed to handle a probably maximum flood.
\end{abstract}

\section{INTRODUCTION}

Dams whose failure could cause loss of life or massive property damage are designed to withstand a probable maximum flood (PMF), but the PMF in many locations has been increased periodically, resulting in spillways that no longer meet the design criterion. To meet this criterion, existing dams must be retrofitted or new ones built with sufficient excess capacity to meet future PMFs. Both alternatives are expensive and become controversial during an era of constrained budgets.

The design criterion that a potentially high hazard dam withstand a PMF represents an implicit balancing of risks and benefits. Since increasing the capacity of the spillway is expensive, it makes no sense to build one large enough to pass the largest possible flood. Rather, engineering experience and judgment have been the basis for estimating a plausible worst case (the PMF) and designing dams to survive it. The success of these judgments is shown in the low rate of dam failure, but recent revisions in the PMF and consequent requests for funds to retrofit existing federal dams have met Congressional resistance. With too many claimants competing for available funds, Congress appears to think that retrofitting to a revised PMF is needlessly conservative. The National Research Council (NRC) [1985] study recognized explicit balancing of risks and benefits as the ideal, but noted that tools did not yet exist to do this balancing with confidence. This paper contributes to the development of these tools.

The objective of dam design should not be to minimize the chance of failure, since that would lead to never building a dam or "goldplating" them. Rather, the objective should be to maximize net social benefits from the dam, considering the cost of construction, and the benefits of flood control, recreation, water supply, power generation, and other effects such as those on the environment. Preventing dam failure is not an end in itself, but rather a way of controlling flood losses and preserving an expensive investment. Four steps must be surmounted to accomplish this balancing of risks and benefits: the first is estimating the size distribution of extreme floods at a particular location; the second is estimating the cost of expanding a spillway to handle a larger flood; the third is estimating the losses both from spilling a flood and from dam failure; and the fourth is balancing the risks and benefits explicitly.

\section{Copyright 1987 by the American Geophysical Union.}

Paper number 7 W0626.

$0043-1397 / 87 / 007 \mathrm{~W}-0626 \$ 05.00$

\section{Current Practices}

The NRC [1985] study included a comprehensive overview of current practices for dam safety design in the United States. of a large number of organizations surveyed, $70 \%$ reported that they used some variant of the PMF in sizing spillways. Those who use return periods for sizing usually do so in a nonspecific way without accounting for the particular characteristics of a project.

Dams are usually characterized as high, medium, or low hazard in a way which is not uniform across agencies. Highhazard dams are sized using the PMF. For lower hazard dams, current practice includes use of somewhat arbitrary criteria, such as $150 \%$ of the 100 -year flood. There is little attempt to characterize the frequency distribution of large floods or the resulting damage. The consensus on using extremely conservative (plausible worst case) criteria for high-hazard dams is not surprising, but this approach offers little guidance for less hazardous dams. The explicit balancing of risks and benefits might lead to different decisions on spillway capacity, especially for low-hazard dams, and more specifically, it promises a firmer basis for multimillion dollar decisions.

\section{Frequency Distribution of Large Floods}

The first step to be surmounted is characterizing the frequency distribution of large floods. Gumbel [1945] introduced the use of theoretical distributions for modeling floods. Researchers have sought the most suitable distribution, but no definitive answer is likely for two reasons: (1) different distributions may be more appropriate for different sites and (2) data are available for only about a century, while interest is in floods of return periods greater than 500 years. No runoff data are available to estimate a PMF, and there are questions about whether such data could be available because of known shifts in climate (such as those due to greenhouse gases [Clark, 1982]. The probability density functions (pdf) of four of the most commonly used distributions are shown in Table 1. They are the two-parameter lognormal (LN2), three-parameter lognormal (LN3), log-Pearson type III (LP3), and extreme value type I (EVT1) [Landwehr et al., 1980; Bobee, 1975; Sangal et al., 1970; Jain et al., 1987]. All four distributions are plausible and there are no strong theoretical reasons to prefer one.

A request for the longest systematic record was made to the Program Office of the National Water Data Exchange (NAWDEX) of the U.S. Geological Survey (USGS). Data covering 87 years for the Rio Grande river were obtained from station 08279500 at Embudo, New Mexico. The peak annual 
TABLE 1. Probability Functions Selected for Flood Frequency Analysis

\begin{tabular}{lll}
\hline Distribution & \multicolumn{1}{c}{ Probability Density Function } & Parameters \\
\hline LN2 & $f_{y}(y)=\frac{1}{y \sigma_{x}(2 \pi)^{1 / 2}} \exp \left(-\frac{1}{2 \sigma_{x}^{2}}\left(\ln (y)-m_{x}\right)^{2}\right)$ & $m_{x} \sigma_{x}$ \\
LN3 & $f_{y}(y)=\frac{1}{(y-a) \sigma_{x}(2 \pi)^{1 / 2}} \exp \left(-\frac{\left[\ln (y-a)-m_{x}\right]^{2}}{2 \sigma_{x}^{2}}\right)$ & $a, m_{x}, \sigma_{x}$ \\
EVT1 & $f_{y}(y)=\alpha \exp (-\alpha(y-\mu)-\exp (-\alpha(y-\mu)))$ & $\alpha, \mu$ \\
LP3 & $f_{Y}(y)=\frac{1}{|a| \Gamma(b) y} \exp (-(\ln y-c) / a)\left(\frac{\ln (y-c)}{a}\right)^{b-1}$ & $a, b, c$ \\
\hline
\end{tabular}

flows are shown in Figure 1. The sample mean $\bar{x}$, variance $s^{2}$, and coefficient of skewness $\gamma$ are $\bar{x}=146 \mathrm{~m}^{3} / \mathrm{s}, s^{2}=9433$ $\mathrm{m}^{6} / \mathrm{s}^{2}$, and $\gamma=0.941$. The four distributions were fitted to the peak annual flow data and the resulting estimates and implications were used to compare the distributions.

The distribution parameters of EVT1, LN2, and LN3 were obtained from maximum likelihood estimates [Jain et al., 1987; Aitcheson et al., 1957]; those of LP3 resulted from the method proposed by Phien and Hira [1983] which uses the first two moments of the original data and the second moment of the log-transformed observations. For simplicity, the goodness of fit was measured by comparing the residual sum of squares (RSS) for each distribution. An important drawback of this approach is that the RSS does not emphasize the quality of fit in the region of major concern, the extreme right hand tail. The respective RSS for each of the fitted distributions are shown below.

\begin{tabular}{cc} 
Distribution & RSS \\
\hline EVT1 & 3450 \\
LPT3 & 3470 \\
LN3 & 3594 \\
LN2 & 3705
\end{tabular}

EVT1 and LP3 fit the data better than LN3; LN2 fits that data much less well. All four distributions give good characterizations of floods for the magnitudes observed. Extrapolating out to the extreme right-hand tail of a distribution fitted to small floods is an act of faith, as well as a belief that one has the correct distribution and good parameter estimates. Nonetheless, since that is the goal of this exercise,

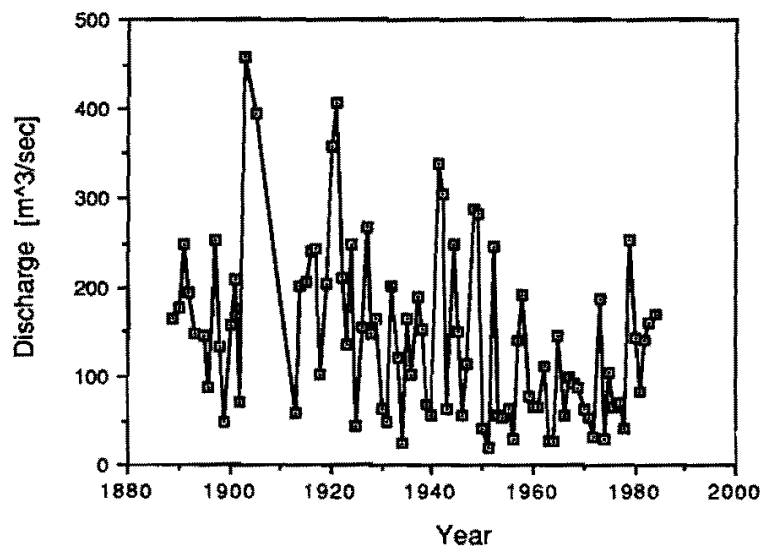

Fig. 1. Peak annual flows for the Rio Grande river at Embudo, New Mexico.
Table 2 shows a comparison of the 500- and 1,000-year floods from the four distributions. EVT1 and LP3, the better fitting distributions, are quite similar in the estimated magnitude of extreme floods, while the two lognormal distributions give much larger values.

The PMF at this site is estimated by the USGS to be 850 $\mathrm{m}^{3} / \mathrm{s}$. The return period for this PMF is shown for each of the four distributions in Table 2. If the PMF were thought of as a 10,000 - to 100,000-year flood, EVT1 seems to do the best job of characterizing it. LP3 indicates the PMF is extraordinarily unlikely, while the two lognormal distributions indicate a return period for the PMF that is implausibly small; the extreme right-hand tail of these distributions is shown in Figure 2. EVT1 emerges as the preferred distribution according to the goodness of fit and PMF criteria. Chong and Moore [1983] found the same result with larger differences. Although LP3 was first recommended by the U.S. Water Resources Council [1976], it seems to understate large floods, to entail a large computational burden, and to present some theoretical limitations [Wallis et al., 1985; Landwehr et al., 1978] relative to the other three distributions.

\section{Cost of aN EXPanded SpILLWAY}

There is no dam at Embudo, New Mexico; to estimate the costs of an expanded spillway, the second step, a Corps of Engineers multipurpose dam at Yatesville Lake, Kentucky was used. This dam is of recent vintage and is approximately the correct size; it is an earthfill type with a total construction cost of $\$ 25$ million 1986 U.S. dollars. The proportion of total project costs spent on the spillway varies with its capacity, the type of construction, and location. For earth and rock fill dams with spillway sized to a PMF, this ratio was found to range from 0.1 to 0.4 , depending on the location and various constraints. For concrete dams, the ratio was found to range from 0.04 to 0.07 . While the ratio should be computed for the particular dam being examined, these ranges appear to be reasonable characterizations of the ratio.

Depending on capacity and location, the cost of a spillway

TABLE 2. 500 and 1000 -Year Floods and Return Period $T$ for the PMF from the Four Distributions

\begin{tabular}{lccr}
\hline Distribution & 500 Year & 1000 Year & $T$ Year (PMF) \\
\hline EVT1 & 550 & 599 & 33,000 \\
LP3 & 547 & 585 & $11,000,000$ \\
LN3 & 732 & 839 & 1,100 \\
LN2 & 928 & 1085 & 350 \\
\hline
\end{tabular}

Flood magnitudes are given in cubic meters per second, and return periods are given in years. 


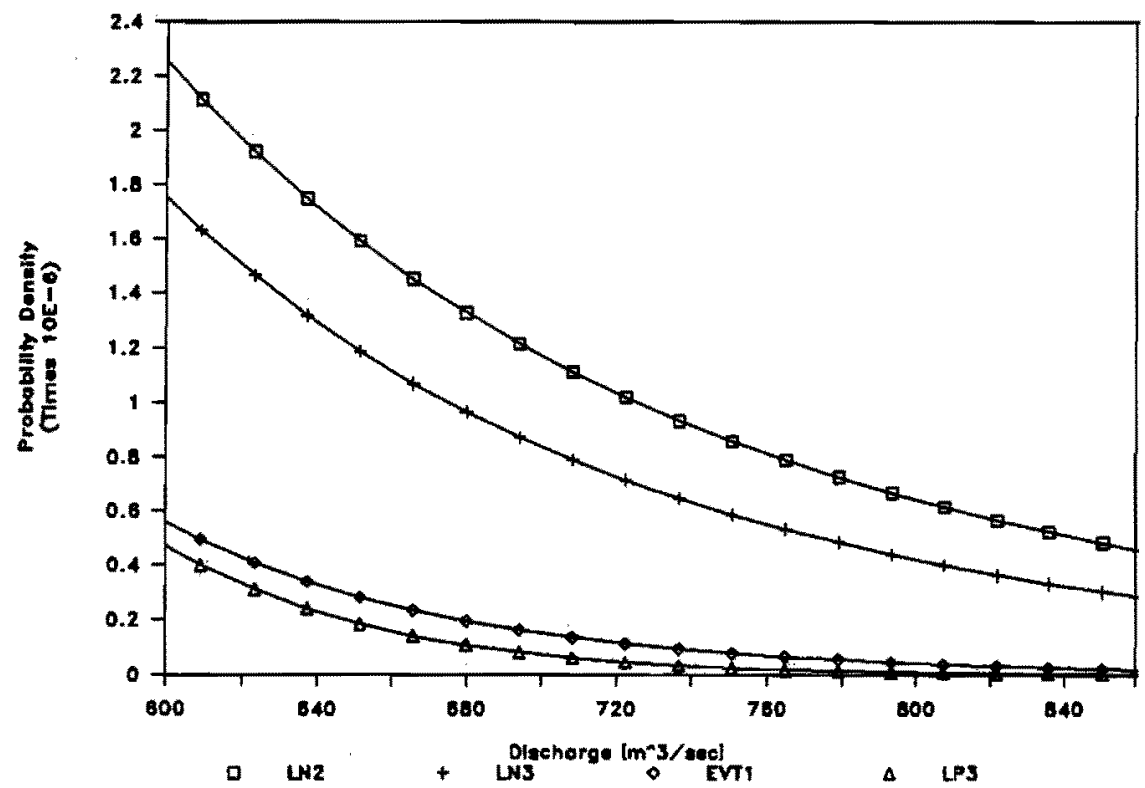

Fig. 2. Right-hand tail of the distributions (EVT1, LP3, LN3, and LN2).

might rise proportionally more or less than an increase in capacity. For simplicity, the cost of a spillway $C_{s}$ is assumed to be proportional to capacity, as shown in (1):

$$
C_{s}=m Q
$$

where $Q$ is the spillway capacity in cubic meters per second. For a new dam similar to that at Yatesville, a spillway that would handle a PMF of $850 \mathrm{~m}^{3} / \mathrm{s}$ is assumed to cost $35 \%$ of the total construction cost or $\$ 8.75$ million while the dam itself costs $\$ 16.25$ million. These assumptions imply $m=10,294$.

\section{Costs of Spilling a Flood and of Dam Failure}

The third step is to estimate the losses from spilling a flood and from dam failure. For a flood whose peak flow is small compared to the peak flow resulting from failure, failure would vastly increase flood damage. However, for a flood whose peak flow is much larger than that resulting from dam failure, failure would not increase flood damage. Costs to society associated with dams can be divided into construction and flood damage costs. Construction costs $C_{\mathrm{c}}$ are determined by the cost of the spillway $C_{s}$ and the cost of the dam $C_{d}$. Flood damage costs $D$ are the losses of property and lives. Flood damages can be expected to increase with peak flow passed through the dam. This damage level can be estimated for each dam. The result is highly dependant on the particular characteristics (topography, demography, operation policy, and reservoir capacity, etc.) of each site.

The probability associated with a particular damage level is directly related to the first step addressed above, namely, the frequency distribution of large floods. Damages can be assumed to be zero for any discharge less than some minimum flood $q_{m}$ (see Figure 3). For any flood larger than some catastrophic flood $q_{c}$, damages can be assumed not to increase with peak flow, since they are already equal to the total value of assets $T$ subject to flood damages. Also shown in Figure 3 is the distribution of floods, $p d f(q)$. If $D(q)$ is the monotonic damage function and $q$ denotes the flood discharge, then dam- ages $D$ are given by

$$
\begin{array}{ll}
D=0 & q \leq q_{m} \\
D=D(q) & q_{m}<q \leq q_{c} \\
D=T & q>q_{c}
\end{array}
$$

For simplicity in this hypothetical example, we assume that the costs associated with the temporary interruption of the flow of benefits derived from the existence of the dam are much smaller than dam replacement costs. We also assume that the benefits of water supply, power generation, flood control and recreation do not vary with the capacity of the spillway, over the range of spillway capacities considered. If these two assumptions hold, society maximizes net benefits by minimizing the sum of construction and flood damage costs.

MacDonald and Langdridge-Monopolis [1984] specify relationships for estimating the shape, size, and development time of the breach for an overtopped dam, as well as the peak outflow of the water released during failure. Using these relationships, we estimate the peak outflow in case of failure of the Yatesville dam during overtopping to range from 565 to $900 \mathrm{~m}^{3} / \mathrm{s}$. The results of this analysis for this particular dam suggest that failure during a PMF of $850 \mathrm{~m}^{3} / \mathrm{s}$ or more might not increase downstream damage. With the information avail-

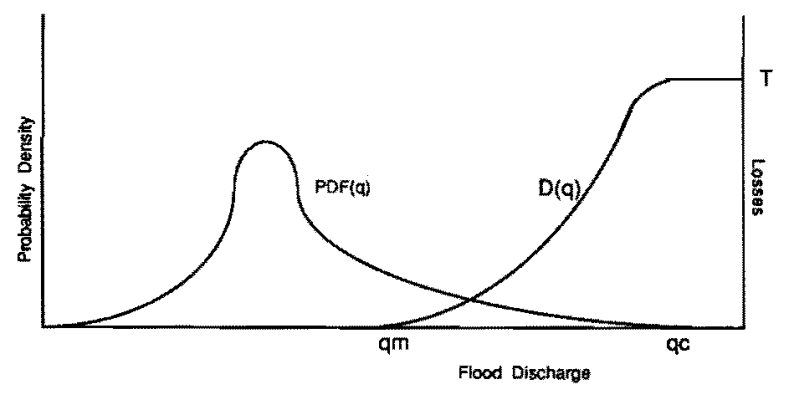

Fig. 3. Damage and probability density functions as a function of flood discharge. 
able for the Embudo, New Mexico, site it is not possible to estimate the damage function. However, for any particular dam, flood losses could be estimated as a function of peak flow and duration.

\section{Explicit Balancing of Risks and Benefits}

Increasing levels of safety can only be achieved at increased expense; the costs of providing that safety and its associated benefits must be balanced. Construction and flood damage costs, as defined above, can be expressed in annual terms. Construction costs need to be multiplied by the capital recovery factor $r$. Damage losses depend on the annual probability $P$ that the spillway's design flood will be exceeded. The value of $P$ is determined by the distribution and estimated parameters used to model extreme floods and constitutes an important source of uncertainty. In general, $P$ has not been explicitly considered in the design of dams. Multiplying damage costs by $P$ permits us to express the expected damage costs in annual terms. Therefore under the assumptions of costs of interruption in flow of benefits being much smaller than replacement costs, of benefits not being correlated with dam or spillway stze, and of failure occurring in the $q>q_{c}$ range (see Figure 3), the objective is to minimize total annual costs $A_{c}$ expressed as

$\min A_{c}=\left(C_{d}+m Q\right) r+\left(C_{d}+m Q\right) P=\left(C_{d}+m Q\right)(r+P)$

Equation (2) is a function of the design flood $Q$ only. $P$ can be written as $P=1-F(Q)$, where $F(Q)$ is the cumulative distribution function (cdf) of the distribution which provides the best fit. When there exists no closed expression for the cdf, as is the case of LN2, LN3, and LP3, numerical integration of the pdf is required.

Table 3 presents the social cost minimizing values of the design flood $Q$ and their associated total annual costs for three different interest rates assuming an expected life of 60 years for a new dam with the physical characteristics of the dam at Yatesville. The higher the interest rate, the smaller the social cost minimizing design flood and the larger is cost. Figure 4 shows the associated total annual cost curves for one interest rate $(i=9 \%)$ for three of the four distributions fitted. Optimal design floods do not seem to be particularly sensitive to interest rates, since they range from 507 to $594 \mathrm{~m}^{3} / \mathrm{s}$ for EVT1. They are considerably smaller than the PMF of $850 \mathrm{~m}^{3} / \mathrm{s}$. These results confirm the conservative nature of the PMF approach and indicate the magnitude of the deviations from social cost minimizing incurred by using such an approach Our assumption that flood losses do not increase with dam failure is progressively a less good assumption as the flood size decreases below an extreme flood (PMF size, for example);

TABLE 3. Optimal Values of $Q$ and the Corresponding Annual Costs

\begin{tabular}{ccccccccc}
\hline & \multicolumn{2}{c}{$i=3 \%$} & & \multicolumn{2}{c}{$i=6 \%$} & & \multicolumn{2}{c}{$i=9 \%$} \\
\cline { 2 - 3 } Distribution & $Q^{*}$ & $A_{c}^{*}$ & & $Q^{*}$ & $A_{c}^{*}$ & & $Q^{*}$ & $A_{c}^{*}$ \\
\hline EVT1 & 594 & 833 & & 538 & 1400 & & 507 & 2021 \\
LP3 & 605 & 827 & & 566 & 1398 & & 538 & 2024 \\
LN3 & 708 & 904 & & 623 & 1497 & & 595 & 2139
\end{tabular}

Optimal design floods are given in cubic meters per second and costs are given in thousands of dollars. that is, when the flood $q$ which causes failure is considerably smaller than $q_{c}$. In an analysis that explicitly calculated flood losses, the social cost minimizing capacity spillway would be larger than that calculated here.

The method presented here also permits us to estimate the cost associated with the deviations from optimal results. We examine the explicit comparison of benefits and costs when a conservative criterion (the PMF, for example) is used for design instead of selecting social cost minimizing values. For the example studied here, if the dam is designed for the PMF, then the flood damage costs are $D=\$ 774$ and the construction costs $C_{c}=\$ 2.263$ million. Designing for the optimum value of $Q$ according to the criterion explained above would result in higher flood damage $D=\$ 74,519$ and somewhat lower construction costs $C_{c}=\$ 1.947$ million. The benefits $B$ of the more conservative design would be given by the reduction in $D(B=\$ 74,519-\$ 744=\$ 73,745)$. The costs $C$ would result from the increase in $C_{c} \quad(C=\$ 2.263-$ $\$ 1.947=\$ 0.316$ ). Thus designing for the PMF gives $B-C=$ $-\$ 242,000$ and $B / C=0.23$. Adopting a conservative approach would increase expected annual costs by almost one quarter million dollars during each of the 60 years of expected life of the project. For the case in which the engineer needs to decide whether to retrofit the spillway of an existing dam after an increase in the estimated PMF, the model presented here, with slight modifications, can be used. The parameters must be fitted to this case. Retrofitting the spillway can be justified if and only if the resulting social cost minimizing value of $Q$ corresponds to net annual costs which are less than the constant net annual costs associated with the existing dam.

\section{UNCERTAINTY ANALYSIS}

A number of issues influence the confidence one can have in the estimates. The first is that the data cover only a relatively short period and are unlikely to include a flood nearly as large as a PMF. If the underlying process leading to floods is stable over time and is well-characterized by the EVT1 distribution, available data can be used to estimate the parameters of the distribution and thus to form a basis for estimating the size and frequency of large floods. As can be seen in Table 2, it makes a great deal of difference which distribution is fitted to the data. We find that EVT1 and LP3 fit the data better than the lognormal distributions and these two distributions have more plausible implications. In this case, the choice among distributions might be made on the basis of computational difficulty and the plausibility of the fitted distribution.

If the peak flow data were drawn from a stationary distribution well characterized by EVT1, they will lead to unbiased estimates of the distribution parameters. However, the smaller the data sample available, the less precise will be the parameter estimates.

Using an approach akin to the "jackknife" technique [Efron, 1982; Mosteller and Tukey, 1977], we have characterized the flood size that would be estimated by having data available for 20 years. From our original data base, we randomly selected 15 data sets of length 20 years $(n=20)$. For each set, we obtained the maximum likelihood estimates of the parameters of the EVT1 distribution. Thus for sample size 20 we estimated the parameters of this distribution 15 times. We then calculated the size of the 500 -year flood associated with each estimated EVT1 probability density function and,calculated the mean and standard deviations of these floods. These 


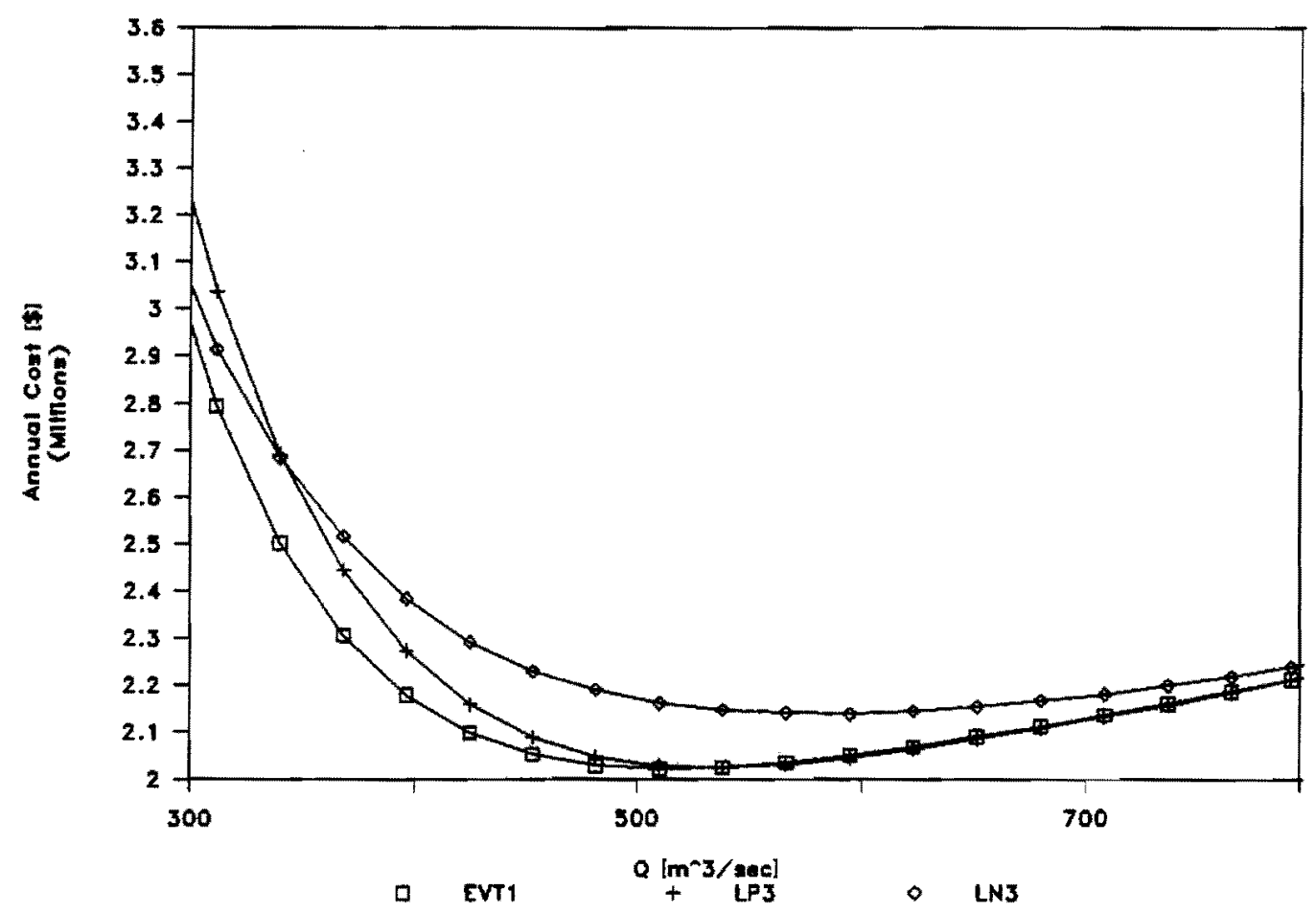

Fig, 4. Total annual cost curves when floods are distributed EVT1, LP3, and LN3.

calculations were repeated for sample sizes of 40 and 60 . The results are graphed in Figure 5. As the sample size increases, the standard deviation falls, as would be expected. With one small exception, the standard deviation on either side of the mean of each sample size falls within the range of the smaller sample size distribution to its left. As would be expected, as the sample size increases, the estimated means of these distributions converge to the 500 -year flood estimated with sample size 87.

Somewhat surprisingly, the means across the different sample sizes range only from $520 \mathrm{~m}^{3} / \mathrm{s}$ to $560 \mathrm{~m}^{3} / \mathrm{s}$. In addition, the standard deviation associated with sample size 20 is only $90 \mathrm{~m}^{3} / \mathrm{s}$. Thus even the range is not terribly large. To our surprise, a sample size of 20 appears to give a reasonable characterization of the underlying flood distribution and thus of the 500-year flood.

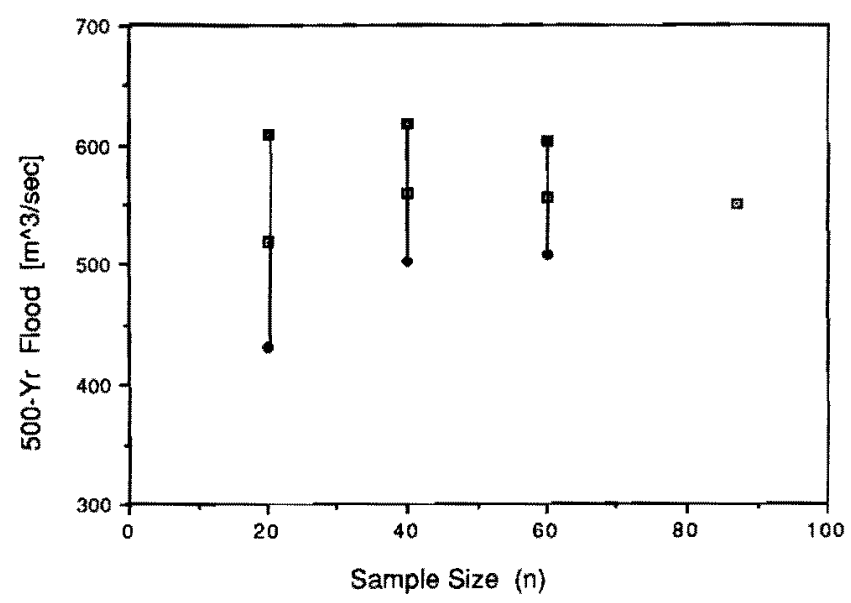

Fig. 5. One standard deviation intervals around the mean 500 year flood for different sample sizes $n$.
If annual peak flows are not drawn from a stationary distribution, the parameter estimates are biased, no matter how large is the sample size. For example, if peak flows are increasing over time, a distribution fitted to current data will underestimate peak flows in the future. There is no consensus on whether peak flows are expected to increase or decrease over time, but it is evident that there are cycles that would have to be accounted for in estimation.

Another issue is how sensitive are the social cost minimizing values $Q$ and $A_{c}$ in view of errors in estimating the parameters of the pdf. A simple way of finding out is by introducing an error term in (2). Introducing this deviation $\varepsilon$ into the cdf of the EVT1 (which provided the best fit to the Rio Grande data) yields

$$
A_{c}=\left(C_{d}+m Q\right)(r+1-\exp (-\exp \{-\alpha \varepsilon(Q-\mu \varepsilon)\})
$$

The error is nonexistent when $\varepsilon=1$ and then grows larger as $|1-\varepsilon|$ increases. It was found that the social cost minimizing values of both $Q$ and $A_{c}$ are sensitive to parameter variability. For $\varepsilon>1$, the effect is small, but if $\varepsilon<0.8$ there are drastic increases in the design flood and, consequently, in annual costs. The proper estimation of the parameters seems to be, within the field of flood frequency analysis, an issue of more importance than the search for a "parent distribution."

\section{Risk ANALYsis}

The estimated frequency of floods and the resulting damage constitute a risk analysis similar to that done for nuclear reactors [Risk Analysis, 1984] carcinogenic chemicals in the environment [Hoel et al., 1985] and food additives [Ames, 1987]. The most difficult events to analyze are the low-probability, high-consequence events, such as dam failure due to an extreme flood [Lave et al., 1985]. For this class of events, it is extremely difficult to get good estimates of the frequency of 
occurance, since these events are so rare. Of lesser difficulty, but still not easy, is estimating the losses associated with such an event, since they are observed so infrequently. In view of uncertainty about the parent distribution, parameter estimates, and possible shifts in the underlying distribution over time, there are good reasons to build spillways somewhat larger than these calculations would indicate.

The estimates of both frequency and loss are uncertain and must be treated as subject to large errors. The estimates are used not because they are appealing or easily defended, but rather because there is little alternative. The absence of numerical estimates means that judgments are used, generally on the basis of little or no analysis. While fitting one of these distributions to 20 years of data leaves the analyst with reservations about the extent to which the distribution of floods is well estimated, and thus about the certainty of the resulting PMF estimate, this procedure makes use of the available data and can be described systematically. The risk analysis provides better information for decisions [Lave, 1987]. The U.S. federal agencies have come to depend on risk analysis as the basis for many decisions [Hoel et al., 1985].

In addition to the uncertainty of the estimates, our estimate of the social cost minimizing spillway capacity must be qualified by the public's risk aversion concerning the failure of dams, nuclear reactors, bridges, etc. [Okrent, 1987]. Estimating the degree of risk aversion is difficult and there is no consensus on how to account for it in practice.

Nonetheless, this method offers a systematic approach that uses the available data and can be subjected to scientific evaluation; if errors are made, the method can be examined and the causes of the problem found. The method focuses attention on the uncertain engineering and policy decisions, promising future improvements.

\section{CONCLUSION}

Sizing dam spillways is an important, difficult decision given the huge costs of dam failure and the high costs of building an unnecessarily large spillway. Fitting appropriate distributions to peak flow data provides a systematic approach to characterizing extreme floods for an area. For the example analyzed, one distribution fits the data best and gives a reasonable return period for the estimated PMF. For a flood as large as a PMF at a dam with a relatively small reservoir, a reasonable assumption is that dam failure would not increase flood damage much over that due to a spilled PMF. This assumption and the estimated relationship allowed us to derive an explicit expression for the sum of spillway construction costs and expected costs of dam failure. For the case examined, this social cost is minimized by sizing the spillway to pass a flood far smaller than a PMF.

The calculations are illustrative rather than the basis for a real decision, since there is no dam at the site analyzed. However, the method is systematic and logical, uses available data, and comes to a sensible conclusion. In application to a particular site, the first part of the analysis, involving fitting a peak flood distribution model, would proceed in precisely the way shown. Increases in flood damage from dam failure and the cost of increased spillway capacity would be estimated for the particular site and project examined. The analysis indicates the spillway capacity that minimizes social cost, as well as the net social cost of building a spillway larger or smaller than this capacity.

\section{Notation}

$A_{c}$ total annual costs associated to the dam.

$C_{c}$ construction costs for the whole dam project.

$C_{d}$ costs of the dam only.

$C_{s}$ cost of the spillway as a function of its capacity, computed as $C_{s}=m Q$.

$D(q)$ flood damages as a function of flood discharge $q$.

$\varepsilon$ error term.

$F($ ) cumulative distribution function of ( ).

$\gamma$ sample coefficient of skewness.

$i$ interest rate.

LN2 two-parameter lognormal distribution.

LN3 three-parameter lognormal distribution.

LP3 log-Pearson type III distribution.

$m$ marginal spillway cost.

$P$ annual probability that the spillway's design capacity $Q$ will be exceeded.

$q$ flood discharge.

$Q$ spillway's design capacity (design flood).

$Q^{*} \quad$ optimum value of $Q$.

$q_{c}$ catastrophic flood which determines the inferior limit for flood damages equal to $T$.

$q_{m}$ largest flood for which flood damages are zero.

$r$ capital recovery factor.

$s^{2}$ sample variance.

$\bar{x}$ sample mean.

RSS residual sum of squares.

$T$ total value of assets subject to flood damage.

Acknowledgments. We thank F. McMichael, M. Small, and A. Epstein for helpful comments, Ms. Peters at NAWDEX and L. Beal at U.S. Geological Survey, Albuquerque, New Mexico, for the data, and the National Science Foundation for research support under grant CES-86 19699.

\section{REFERENCES}

Aitcheson, J., and J. A. C. Brown, The Lognormal Distribution, Cambridge University Press, New York, 1957.

Ames, B., R. Magaw; and L. Gold, Ranking possible carcinogenic hazards, Science, 236, 271-279, 1987.

Bobee, B., The log Pearson type 3 distribution and its application in hydrology, Water Resour. Res., 11(5), 681-689, 1975.

Chong, S., and S. M. Moore, Flood frequency analysis for small watersheds in southern 1llinois, Water Resour. Bull., 19(2), 277-282, 1983.

Clark, W. (Ed.), Carbon Dioxide Review: 1982, Oxford University Press, New York, 1982

Efron, B., The Jackknife, the Bootstrap and Other Resampling Plans, Society for Industrial and Applied Mathematics, Philadelphia, Pa., 1982.

Gumbel, E. J., Floods estimated by probability method, Eng. News$\operatorname{Rec}_{.,}, 134,97-101,1945$.

Hoel, D., R. Merrill, and F. Perera (Eds.), Risk quantification and regulatory policy, Banbury Rep. 19, Cold Spring Harbor Lab., New York City, 1985.

Jain. D., and V. P. Singh, Estimating parameters of EVI distribution for flood frequency analysis, Water Resour. Bull., 23(1), 59-71, 1987.

Landwehr, J. M., N. C. Matalas, and J. R. Wallis, Some comparisons of flood statistics in real and log space, Water Resour. Res., 14(5), $902-920,1978$.

Landwehr, J. M., N. C. Matalas, and J. R. Wallis, Quantile estimation with more or less floodlike distributions, Water Resour. Res., 16(3), $547-555,1980$.

Lave, L. B., Health and safety risk analyses: Information for better decisions, Science, 236, 291-295, 1987.

Lave, L. B., and J. Menkes, Managing risks: A joint U.S. German perspective, Risk Anal., 5, 17-25, 1985. 
MacDonald, T. $C$ and J. Lengridge-Monopolis, Breaching character* istics of dame failures, J. Hydraul. Eng, I 10(5), 567-586, 1984.

Mosteller, F, and I. W. Tukey, Data Analysis and Regression, Addison-Wesley, Reading, Mass, 1977.

National Research Council, Safery of Dawn, Flood and Earthquake Criteria, National Academy Press, Washington, D.C., 1985.

Okreat, D. The arety gask of the U.S. Nuclear Regulatory Commission, Science, 236, 296-300, 1987.

Phien. H. M and M. A. Hira, Log Pearon type-3 distribution: Pa. rameter extimation, J. Hydrol, 64(3), 25-37, 1983.

Risk Analysic Special issue on Nuclear Probabilistic Risk Analysis, Risk Anal _ 44), 247-335, 1984.

Sangal, B. P, and A. K. Biswas, The three-parameter log normal distribution and its applications in hydrology, Water Resour. Res., 6(2) $505-515,1970$.
U.S. Water Resources Council, Guidelines for determining flood flow frequency, Bull. 17, Hydrol. Comm, U.S. Water Resour. Counc., Washington, D.C. 1976.

Wallis, J. R., and E. F. Wood, Relative accuracy of log Pearson III procedures, J. Hydraul, Eng, $11177,1043-1056,1985$.

D. Resendiz-Carrillo and L. B. Lave, Department of Enginecring and Public Policy, Carnegie Mellon University, Piltsburgh, PA 15213. 